\title{
Bis-(3-sulfopropyl) Disulfide Acceleration of Copper Electrodeposition via Molecular Dynamics and Quantum Chemical Calculations
}

\author{
Fuliang Wang ${ }^{1,2}$, Yuping $L e^{1,2, *}$ \\ ${ }^{1}$ School of Mechanical and Electrical Engineering, Central South University, Changsha 410083, China \\ ${ }^{2}$ State Key Laboratory of High Performance Complex Manufacturing, Changsha 410083, China \\ "E-mail: leyuping1@163.com
}

doi: $10.20964 / 2020.06 .11$

Received: 6 June 2019 / Accepted: 4 December 2019 / Published: 10 May 2020

\begin{abstract}
Bis-(3-sulfopropyl) disulfide (SPS) is commonly used as an accelerator for copper electroplating in through-silicon via and printed circuit board fabrication. However, detailed SPS accelerator dynamics have not yet been fully studied. In this study, the adsorption behavior and accelerator dynamics of SPS on a copper surface were studied by using molecular dynamics and quantum chemical calculations. The natural atomic charges, molecular properties, distributions of frontier molecular orbitals, and Fukui indices were obtained. According to the simulations, the SPS reaction cycle on a copper seed layer surface was proposed. In this cycle, the SPS adsorbed on the cathode is attacked by $\mathrm{H}^{+}, \mathrm{Cl}^{-}$, and the oxygen anion of $-\mathrm{SO}_{3} \mathrm{H}$, obtains an electron from the cathode, and breaks into two 3mercaptopropane-1-sulfonic acid (MPS) molecules. Subsequently, two free MPS dimerize into an SPS, releasing an electron to reduce $\mathrm{Cu}^{2+}$ into $\mathrm{Cu}^{+}$. Through this SPS reaction cycle, electrons on the copper seed layer surface (cathode) are transferred to $\mathrm{Cu}^{2+}$ to yield $\mathrm{Cu}^{+}$, thereby accelerating the deposition process.
\end{abstract}

Keywords: Bis-(3-sulfopropyl) disulfide, MD simulation, Quantum chemical calculations, HOMO, LUMO.

\section{$\underline{\text { FULL TEXT }}$}

(C) 2020 The Authors. Published by ESG (www.electrochemsci.org). This article is an open access article distributed under the terms and conditions of the Creative Commons Attribution license (http://creativecommons.org/licenses/by/4.0/). 